\title{
Discussion of Constructing People-Oriented College Student Management Mode
}

\author{
Yijie Qi
}

College of Horticulture, Jilin Agricultural University, Changchun, 130118

qyj101@126.com

\section{Keywords: People-oriented; Colleges and universities; Management mode}

\begin{abstract}
People-oriented is the essential connotation of the outlook on scientific development and important guide to realize comprehensive, coordinated and sustainable development of economy, society and people. Colleges and universities are the main field to transmit high-level and high-quality talents to the society, so only by constructing people-oriented management mode can we effectively achieve this goal. Otherwise, it is also an index to measure the management level of colleges and universities. Whether college student management mode is advanced and adapt to modern social development has important influence on improving students' comprehensive quality. At present, as colleges and universities are constantly expanding the recruitment scale, teaching management reform is constantly deepening and students' minds are becoming increasingly personalized, traditional college student management mode will surely be eliminated. Therefore, colleges and universities must adhere to being people-oriented to innovate management mechanism and innovate management mode.
\end{abstract}

\section{Introduction}

In today's society, with the leaps and bounds of various science and technology and explosive knowledge economy, the competition between countries in terms of economic strength and comprehensive national strength is actually the competition of science and technology. The application of science and technology is the talent, in the final analysis, the competition is the talent competition, talent, science and technology through the country. Efficient is plays an important role in cultivating talents, are clearly defined in the "People's Republic of China higher education law": "higher education should implement the educational policy of the state, serve the construction of socialist modernization, combined with production and labor, make education become socialist builders and successors of all-round development". In colleges and universities, good management is the key to ensure the smooth development of education and teaching work, and improve the effective management system to ensure the efficiency of running a school. Now the university continues to expand the scale, the increasing number of college students' frequent problems, while facing the science and technology revolution, which requires the reform of their management mode. People oriented student management model came into being, the manager and service to the people.

\section{Features of People-Oriented Student Management Mode}

Pay Attention to Students' Comprehensive Development. In the management of colleges and universities, adhere to the people-oriented is to insist on everything from the perspective of students, to meet the needs of students for the work of the end result. To create a good environment for students, promote their all-round development in morality. However, the traditional management of students in colleges and universities and small and medium-sized management model is no different, are in class as a unit, in order to achieve the goal of class management as the focus, ignored the personality development of students. The management model not only pays attention to the collective goals and interests, and care about the individual needs of students, the fundamental goal of management is to promote the development of students, to meet the diversified needs of society, the talent training mode of negative unified model. 
Insist on the Subjectivity of Students. The humanistic management model can effectively reflect the students' autonomy, initiative and creativity. The traditional mode of management is just the students as the object of management, with the system to restrain the students, stifling the student's subjectivity. But many students rebellious, do not match, only allow students to participate in the management work, in order to achieve the effect of management. The management subject, students encounter problems, Daniel, move. This management can through a system to guide and standardize the behavior of students, on the other hand can create environmental impact on students, thus consciously restrain their behavior, recognize the wrong subjectively.

Respect Students' Personality. The growth of students is a process of continuous development; each student has congenital differences, social and plasticity, respect for students' personality to be able to effectively play their creativity. The traditional management mode, teachers love obedient students hope that students too observant of conventional standards, uniform. In fact, it obliterates the personality of the students. The trend of the modern society is also asking people to develop their personality. Adhere to the people-oriented management can cultivate students' imagination and creativity, not sticking to formalities cultivation, guide students to self-management, self-understanding, implementation to promote personal interest.

Reflect the Principle of "Teaching According to Students' Aptitude". During the process of teaching according to students' aptitude, teachers use different teaching methods according to each student's personality, aptitude and master and understanding of knowledge. The traditional management mode is one size fits all, the education goal is unitary, the school is arranged, the student is to listen to the arrangement, completely in the passive. The management mode of the students is the first one, students' elective professional coursework, graduation time and professional exchange are building their own respect, some schools use their own source advantages and also encourage students to choose cross courses, to achieve the sharing of resources, students choose the teacher system gradually there, fully embodies the principle of individualized.

Enhance the Service Awareness of Student Management. The mode of the traditional student management emphasizes the students obey the management, and the students as the object of management, in the quality education of the new situation, has not adapted to the cultivation of innovative talents. In fact, education also belongs to the third industry, that is, the service industry, so colleges and universities should continue to improve the quality of education students. The students come to school to pay, you should get the best service, the managers should pay attention to safeguarding the interests of the students, to provide a variety of resources for students, including the information network platform, borrow books, rich campus cultural life and employment guidance, constantly improve the management responsibility, to the needs of students in first, let the student satisfaction and make parents no worry.

\section{Construct People-Oriented Student Management Mode}

Establish Student-Centered Management Mode. The object of the management of college students is the people, so the innovation of student management mode should adhere to the students as the center, first of all, to create good campus culture environment, including material culture and spiritual culture, the former mainly refers to the inside and outside of the room, the campus green wall, the plum, the latter mainly refers to the campus disciplines, interpersonal relationship and cultural activities the atmosphere, the development process of the students is long-term, family, education and influence by environment, campus cultural environment for students' education and management is subtle and is essential for life, should not be overlooked on the school education and teaching of teachers and students. The campus cultural environment exerts a subtle influence on the students' behavior, and it has the function of cultivating character, binding behavior and encouraging progress, so that students can carry forward the spirit of the main body in a relaxed atmosphere. Secondly, the establishment of student management model. Students' management has an important role in the students' Ideological and political education and ability training, and need the appropriate management to ensure the implementation of this work, therefore, need to improve the corresponding management system. Through the establishment of student self-management 
model, to enable students to achieve their own when the owner, self-constraint, is conducive to play students' creativity and enthusiasm. Student self-management can be responsible for student affairs by setting different departments and agencies. To improve the decision-making management system, command and management system, implementation and supervision and management system to ensure that the management of the various departments and agencies to communicate with each other, in an orderly manner. Departments of various agencies can be adjusted according to the needs of the operation to ensure the smooth development of student management. Again, the students' self-management in the initial stage will have a lot of problems, but also need to be encouraged and guided. Students' self - management is not to deny the help of school teachers and administrators, but only to liberate the students from the traditional mode of being oppressed. Students are adults, usually have their own views of things, the way of doing things, the formation of the outlook on life and values, so this requires the university management should grasp the critical point of management, managers grasp the overall situation in the self- management to students, to help students behavior control and ideological transformation of good.

Establish Perfect Student Management Regulations and System. To rule the country with laws and rule the school with regulations. Only to ensure the authority and correctness of the rules and regulations, in order to serve the people according to law, and truly adhere to the people-oriented. Colleges and universities should help students to improve the legal concept, with the law to protect the rights of individuals, colleges and universities also have to modify and clean up the system to damage the interests of students. Especially in the "Regulations on the management of college students" after the introduction of the system, the requirements of the rules and regulations of the school and the relevant provisions of the state have inherent unity. In addition, in the management of students, dealing with students' problems, should pay attention to the students' mistakes, perfectly logical and reasonable, give priority to the education of students, once the action, need to rely on legal support, to avoid misjudgment, ruin the students' future, but also to ensure the compliance program, let the students have the right to know, the right to defense. College students on the one hand to deal with violations of student behavior, the exercise of supervision and management rights, but also to ensure that other students' interests are not violated. System is dead, people are living, but also the system of human feelings, according to the specific things, to ensure the scientific operation of the system. Finally, colleges and universities in the development of the system, but also to communicate with students in a timely manner, as far as possible to take the views of the majority of students, so that the school's management requirements and the development of students harmonious.

Innovate Student Management Mode. Innovative student management needs to do the following: first, to play an important role in teaching and education of staff. According to humanistic psychology, the most ideal moral education, it is through the teaching process in various disciplines, so that students in the combination of the ideal and practice gradually improve the personality. Never teach the separation, in the process of teaching, teachers and students face to face contact, to better understand the development of students, in the process of educating people to teach permeated with the truth, so the management of college students by teachers can lead full participation, improve their moral accomplishment at the same time, to achieve the management of the students. Second, the method of education management and educational objectives are consistent. The management of college students according to the law of students' physical and mental development and understanding of the level of management personnel must start from the student life experience and experience, help them learn independent judgment, judgment, communication skills and improve the students. Students will also receive education and self-management, and constantly improve their mutual cooperation ability, moral sense of the times and social communication skills. Third, the construction of an efficient political instructor management team. According to the "Ministry of education to strengthen the college counselor, the class adviser team construction opinions" and other related documents to form a strong contingent of counselors management, improve the quality of the whole team, to ensure their regular training instructors, students master the advanced management method, the college counselors should 
develop culture technology, considered as counselors the development of care for their work and treatment, so as to ensure the continuity and stability of student management. Fourth, improve students' evaluation incentive system. The evaluation system has a guiding role for students, spiritual rewards and material rewards and punishments should be combined, so as to effectively mobilize the students' creative talents, students' scientific evaluation mechanism, improve the evaluation mechanism of normative and scientific management is the pursuit of students.

\section{Conclusions}

Traditional student management mode can no longer adapt to the development of information colleges. The author discusses the differences and features of people-oriented college student management mode and traditional mode, and the proposes how to effectively construct modern people-oriented student management mode according to problems in current college student management, which is related to whether college reform can be smoothly carried out. Therefore, it is worth the attention of college management staffs. Hope research in this paper can contribute to the exploration of college student management mode.

\section{References}

[1] Jiang Lu. Reconstruction of college student management mode [J]. Journal of Harbin Finance University, 2010.1.

[2] Ye Lan. Construction of Spirit of the Time and New Education Ideology - Trans-century Reflection on Domestic Basic Educational Reform [J]. Educational Research, 2009(6).

[3] Chen Guozhong, Xu Lingxiao. Rational thinking on the working mechanism of college students [J]. Heilongjiang higher education research, 2003 (4): 54-56.

[4] Yu Xinghan. The new ideas of student management after the enrollment expansion of colleges and universities [J]. Journal of the State Administration of Education, 2004(4):74-76.

[5] Liu Ping. Reflections on the further deepening of the reform of the internal system of universities and colleges [J] Journal of GanNan Normal University, 2002(4)

[6] Zhao Chunlin. Ideological and political work must serve for enhancing students' comprehensive quality [J] Ideological and Political Education, 2003(1)

[7] Peng Zhenglu: Theory and construction of campus culture in Colleges and Universities [M] Chengdu: University of Electronic Science and Technology Press, March 2002

[8] Zhang Jing: The conflict and balance between the management of students and the education of students in Colleges and Universities [J] Hebei Law, 2003(2)

[9] (American) David Mike R. Rosee. Yorick. Gerry. Lake. Future Human Resource Management [M] Beijing: Mechanical Industrial Press, 2003.

[10] Ren Xiujie: Humanistic thought and college students' work [J] Journal of Shandong Youth University of Political Science, 2002(4)

[11] Zhu Yixin: Application of human centered management in the management of college students [J] Journal of East China Shipbuilding Institute, 2001(3) http: //www.moe.edu.cn/news.

[12] Zhou Ji: "Retrospect and Prospect of China's educational reform and development" (2003 2004), website of the Ministry of Education of People's Republic of China, http: //www.moe.edu.cn/news. 